\title{
Characteristics of Exfoliated Graphite Prepared by Intercalation of Gaseous $\mathrm{SO}_{3}$ into Graphite
}

\author{
Beom-Jae Lee \\ Eco-machinery Eng. Dept., Korea Instifute of Wachinery \& Haterials, Daejeon 305-343, Korea \\ Received November 2, 2002
}

\begin{abstract}
The graphite intercalation compounds(GIC) were prepared by a dry process that led to the intercalation from the direct reaction of gaseous $\mathrm{SO}_{3}$ with flake type graphite. The basal spacing of the GIC was increased from $8.3 \mathrm{~A}$ to $12 \mathrm{in}$ the gallery height. The ejection of interlayer $\mathrm{SO}_{3}$ molecules by the heating for 1 nuinute at 950 ${ }^{\circ} \mathrm{C}$ resulted in an exfoliated graphite (EG) with surprisingly high expansion in the direction of $c$-axis. The expansion ratios of the exfoliated graphites were increased greatly between 220 times and 400 times compared to the original graphite particles, and the bulk density was in the range of 0.0053 to $0.01 \mathrm{~g} / \mathrm{cm}^{3}$. depending on reaction time. The pore size distribution of exfoliated graphite was in the range of $10-170 \mu \mathrm{m}$, which exhibites both mesoporosity and macroporosities. This result indicates that the direct reaction of graphite particles with gaseous $\mathrm{SO}_{3}$ can be proposed as an another route for the exfoliated graphite having excellent physical properties.
\end{abstract}

Key Words : Graphite intercalation compound (GIC), Exfoliated graphite (EG). Oil sorption

\section{Introduction}

Exfoliated graphite (EG). which is an important raw material for the industrial production of flexible graphite sheets. sealing. packing and thermal insulator. has attracted attention because of its very high sorption capacity of spilled heavy oils and their easy recovery. Inagaki et $a^{l^{1-3}}$ recently reported that the exfoliated graphite exhibited an excellent adsorption for the spilled oil in water. Graphite intercalation compounds(GIC) as precursors for exfoliated graphite have been studied by using various intercalates. such as $\mathrm{H}_{2} \mathrm{SO}_{4}+.5$ $\mathrm{FeCl}_{3}{ }^{6.7} \mathrm{~K}_{-} \mathrm{THF}^{7}$ formic acid. ${ }^{8}$ etc. ${ }^{5}$ However. in industry: the acid treatments based on the sulfuric acid have been still used as a conventional process leading to the exfoliated graphite. In general the acid treatment of flake graphite is carried out by the wet process in which the flake graphites are immersed in a strongly oxidizing solution prepared by mixing a concentrated sulfuric acid with an oxidizing agents. such as nitric acid. potassium chromate potassium permanganate. hydrogen peroxide etc. Therefore. the discharge of a great quantity of acid waste and its treatment have been pointed out to be troublesome: admixtures of strong acid are troublesome in a process control because of their strongly corrosive property.

$\mathrm{SO}_{3}$ gas molecules as an excellent oxidizing agent can be intercalated into interlayers to attack directly $\pi$-electron in the interlayer of graphite. The direct reaction of flake graphite with $\mathrm{SO}_{3}$ gas can be processed by dry process where $\mathrm{SO}_{3}$ gas is fed through the reactor filled with the graphite particles in an atmospheric condition. In particular. $\mathrm{SO}_{3}$ gas can be supplied by using a byproduct in a chemical process. and the problem of generation of acid waste can be eliminated in this process. therefore. this could solve a problem in the process caused by treating a corrosive and strong acid admixtures in wet process. In spite of this good point. research on using $\mathrm{SO}_{3}$ gas as an intercalation oxidizer has not nearly been conducted.

In this paper, the preparation of exfoliated graphite by the reaction of flake graphite with $\mathrm{SO}_{3}$ gas is reported. The exfoliated graphite prepared by our novel method exhibited no difference in the physical properties. such as the volume expansion, the bulk density, and the oil sorption. compared with that manufactured by the acid immersion method. This result indicates that the dry process can be very effective route leading to the exfoliated graphite.

\section{Experimental Section}

Raw materials used were natural graphite particles $(98 \%$. 50 mesh. Hyundai Coma Ind. Co.. Korea) and oleum (25\% $\mathrm{SO}_{3}$. Namluae Chem.. Korea) as a $\mathrm{SO}_{3}$ source

The reaction of graphite particles with $\mathrm{SO}_{3}$ gas. as shown in Figure 1. was conducted by passing $\mathrm{SO}_{3}$ gas through the reactor filled with the graphite particle in an atmospheric condition. $\mathrm{SO}_{3}$ gas was evaporated by heating at $80-120^{\circ} \mathrm{C}$ the flask filled with $500 \mathrm{~mL}$ of oleum. saturating the upper reactor filled with graphite particle with $\mathrm{SO}_{3}$ gas. The saturation of $\mathrm{SO}_{3}$ gas in a reactor can be ascertained by opening the cock valve connected to the right upper part of reactor. The temperature of the reactor was kept above $25^{\circ} \mathrm{C}$ to prevent the $\mathrm{SO}_{3}$ gas freezing. The intercalation reaction was carried out for $5,10.15$, and 20 hr to prepare $\mathrm{SO}_{3}$ intercalated graphites.

The amount of $\mathrm{SO}_{3}$ loaded in the graphite was calculated from the weight increase of reaction products as a function of a reaction time. Each reaction products before weighing were heated for $1 \mathrm{hr}$ at $100^{\circ} \mathrm{C}$ to remove $\mathrm{SO}_{3}$ molecules simply condensed in the graphite surface. The severe heating of graphite intercalation compounds for $1 \mathrm{~min}$ at $950^{\circ} \mathrm{C}$ brought about an abrupt ejection of interlayer $\mathrm{SO}_{3}$ gas. 


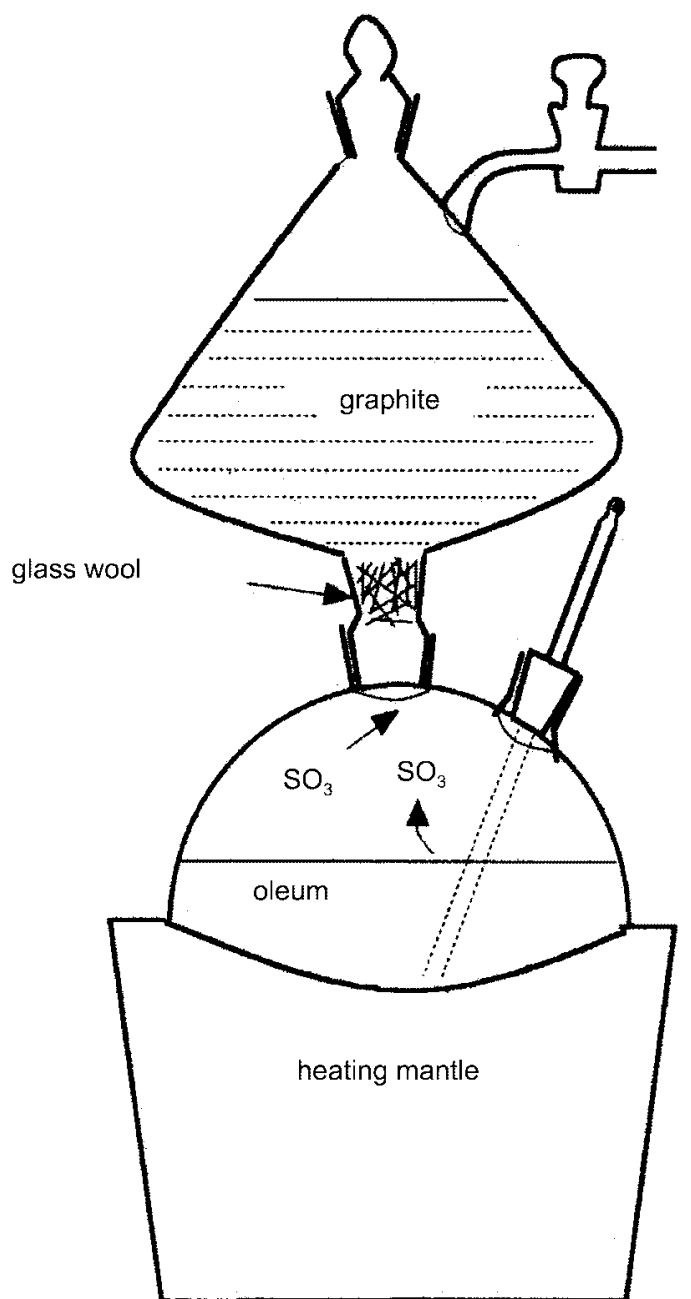

Figure 1. Reaction equipment for the reaction between graphite and $\mathrm{SO}_{3}$ gas.

resulting in the exfoliated graphite. The bulk density was calculated from the volume and the weight. and the volume expansion ratio was determined from the density ratio of exfoliated graphite and raw graphite. The volume of exfoliated graphites was measured in a mass cylinder by treating the exfoliated graphite for $30 \mathrm{~s}$ by the ultrasonic to give uniform packing of exfoliated graphite. To study the sorption capacity of exfoliated graphite four grades of heavy oil were used. such as crude oil. Bunker-A (viscosity of 0.2$0.4 \mathrm{~kg} / \mathrm{ms})$. Bunker-B (1:1 mixture of Bunker-C and Bunker-A viscosity of $15 \mathrm{~kg} / \mathrm{ms}$ ) and Bunker-C (viscosity of $35 \mathrm{~kg} / \mathrm{ms}$ ).

To distilled water. about $400 \mathrm{~mL}$ in a beaker. kept at a room temperature. heavy oil was added and stirred for a while. The exfoliated graphite was added until the floated heavy oil was disappeared from the water surface. completely absorbed in the exfoliated graphite. By changing the weight ratio of heavy oil to that of the exfoliated graphite. the maximum sorption capacity of the exfoliated graphite was determined. The sorption capacity was expressed by the weight of heavy oil sorbed per $1 \mathrm{~g}$ of exfoliated graphite

The intercalation of $\mathrm{SO}_{3}$ molecules into graphite interlayer was ascertained by the X-ray diffraction using a Rigaku diffractometer equipped with $\mathrm{Cu}$ radiation. Samples were ground to powder before the analysis. The surface morphology of the exfoliated graphite was examined with a scanning electron microscope (SEM. JEOL JSM-840). The total pore volume was measured by a mercury porosimeter (Shimazu-Micrometrics. Poresize-9320. Japan).

\section{Results and Discussion}

The blue color is appeared on the graphite particles by initial contact with $\mathrm{SO}_{3}$ gas and it changes gradually to bluish green color, resulting in a volume expansion about 23 times. The wetting of the graphite of blue color was progressively proceeded for initial $5 \mathrm{hr}$ from the botton of the reactor to the upper part. The successive reaction resulted in a great volume expansion. This indicates that $\mathrm{SO}_{3}$ gas is initially adsorbed or condensed in the surface of graphite particle and progressively intercalated into interlayers of the graphite.

Figure 2 shows the amounts of loaded $\mathrm{SO}_{3}$ per g-graphite. which depend on the reaction time. The data represent the amount of intercalated $\mathrm{SO}_{3}$ only because $\mathrm{SO}_{3}$ molecules simply adsorbed or condensed on the surface were fully removed by heating for $1 \mathrm{hr}$ at $100^{\circ} \mathrm{C}$. The amount of loaded $\mathrm{SO}_{3}$ steeply increased for $10 \mathrm{hr}$ and converses to constant. implying that the intercalation was nearly completed after 10 hr.

Figure 3 exhibits the X-ray powder diffraction patterns for the graphite intercalation compounds prepared by the reaction of graphite with $\mathrm{SO}_{3}$ gas for $5,10.15$, and $20 \mathrm{hr}$. respectively: The basal spacing of $3.7 \mathrm{~A}$ in a raw graphite increased to $12.0 \mathrm{~A}$ with a little shift of main peaks after $5 \mathrm{hr}$ reaction. indicating the expansion of $8.3 \AA$ in a gallery height. The gallery height was calculated from the difference in basal spacings of GIC and raw graphite. The basal spacing of a raw graphite is just equal to a lay'er thickness in graphite. This value was two times larger than the value $(\sim 4.6 \mathrm{~A})$ in

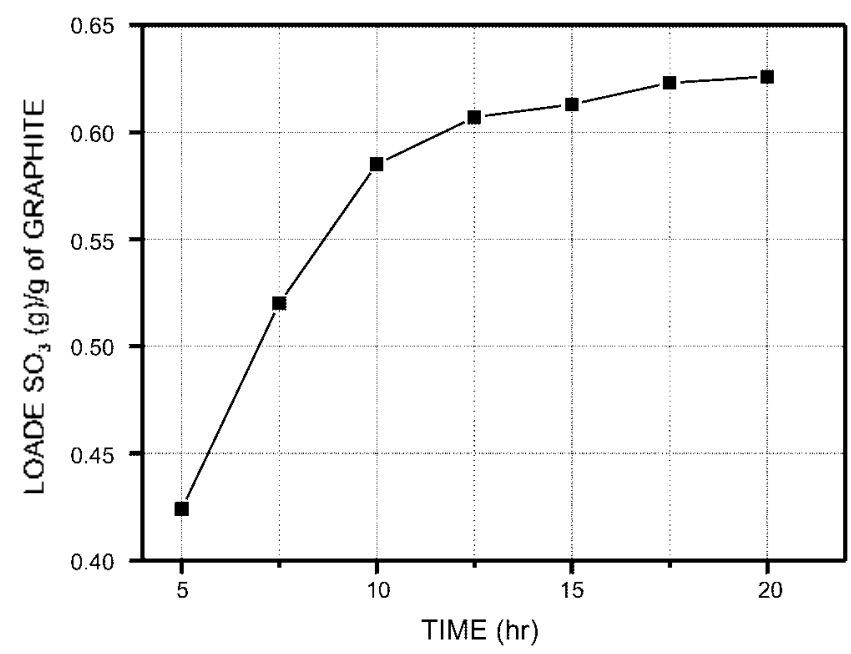

Figure 2. Loaded $\mathrm{SO}_{3}$ gas per g-graphite depending on the reaction time. 

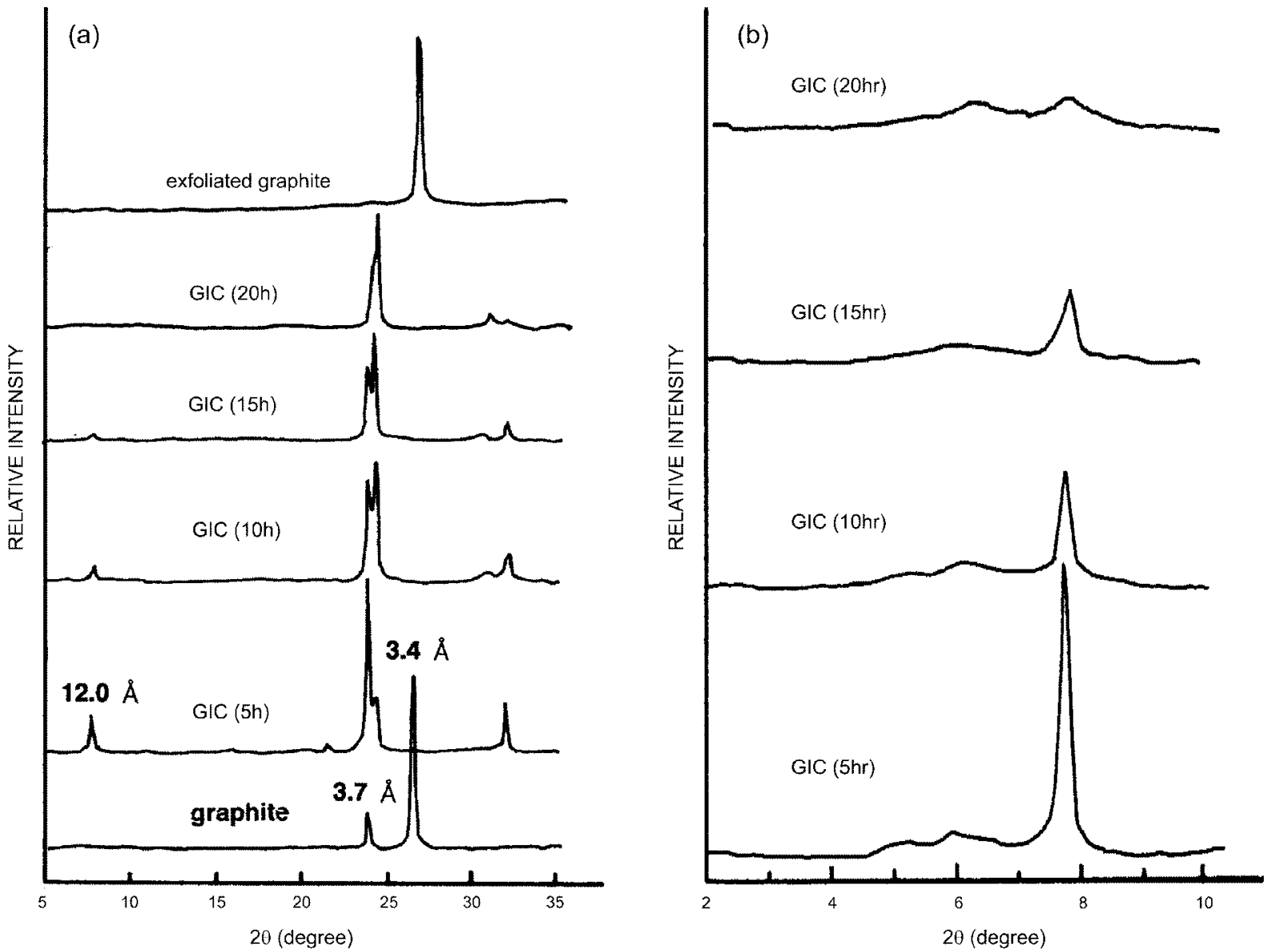

Figure 3. X-Tay diffraction pattens of the $\mathrm{SO}_{3}$ intercalated graphite at various reaction times: (a) $2 \theta .5-35$, (b) $\theta .2-10$.

residue compound of sulfuric acid reported previously. ${ }^{10}$ The 001 diffraction in GIC. however. as shown in Figure 3(b). gradually disappeared with an increasing reaction time. implying the expansion of graphite layers. This indicates that $\mathrm{SO}_{3}$ molecules may be packed with configuration of double or multiple layers in the interlayer. Strong van der Waals interaction between $\mathrm{SO}_{3}$ molecules may lead to large expansion in the gallery height by the interlayer condensation. which reduces the interlayer interaction enough to make exfoliated graphite layers. This explanation is based on that interlayer interaction among graphite layers. and the interlayer interaction is very weak compared with that of other layered materials. The intense peak near $\sim 3.5 \mathrm{~A}$ in a raw graphite was known as 001 diffraction.

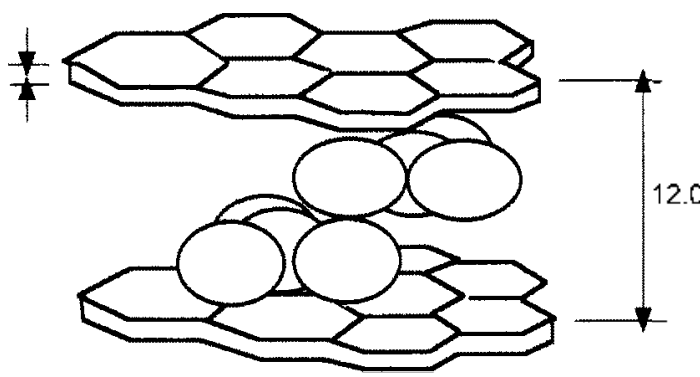

Figure 4. Schematic draws for the hypothetical configuration of $\mathrm{SO}_{3}$ molecules in the graphite interlayer.

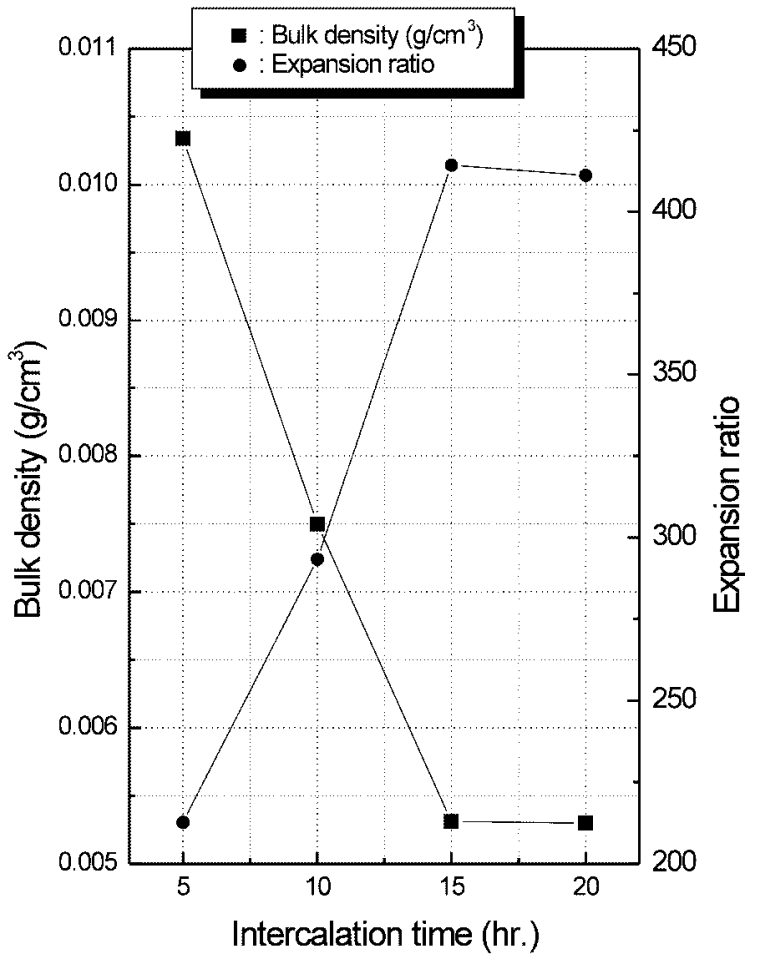

Figure 5. Bulk density and expansion ratio of the exfoliated graphite depending on the reaction temperature. 


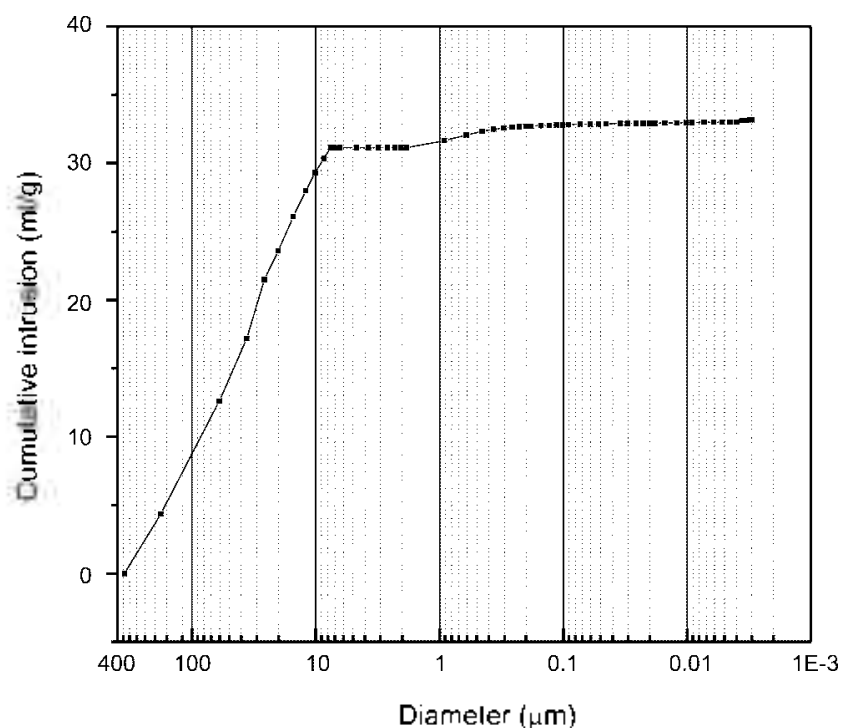

Figure 6. Pore characteristic of the exfoliated graphite by the mercury porosimetry.

Figure 4 shows the hypothetical configuration for $\mathrm{SO}_{3}$ molecules in interlay'er. Supposed that two $\mathrm{SO}_{3}$ molecules with trigonal planar structure are laid one upon another. the

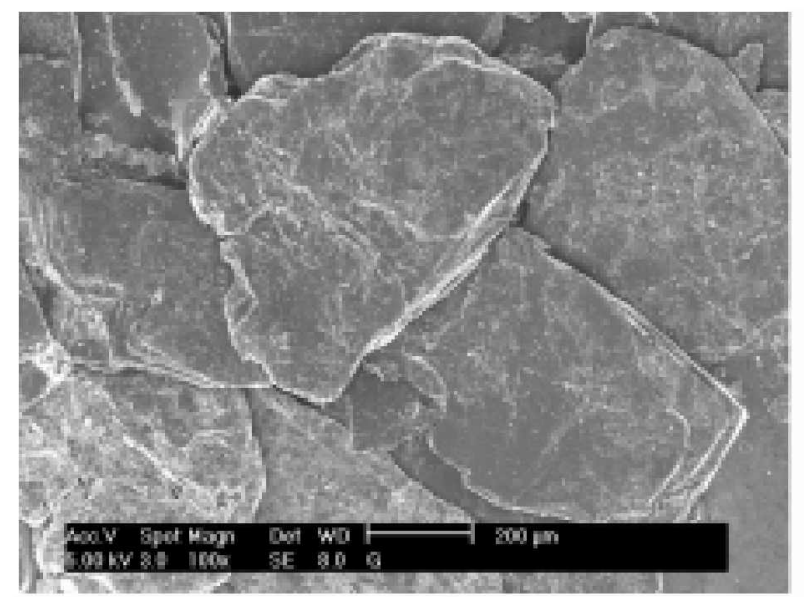

(日) $x 100$

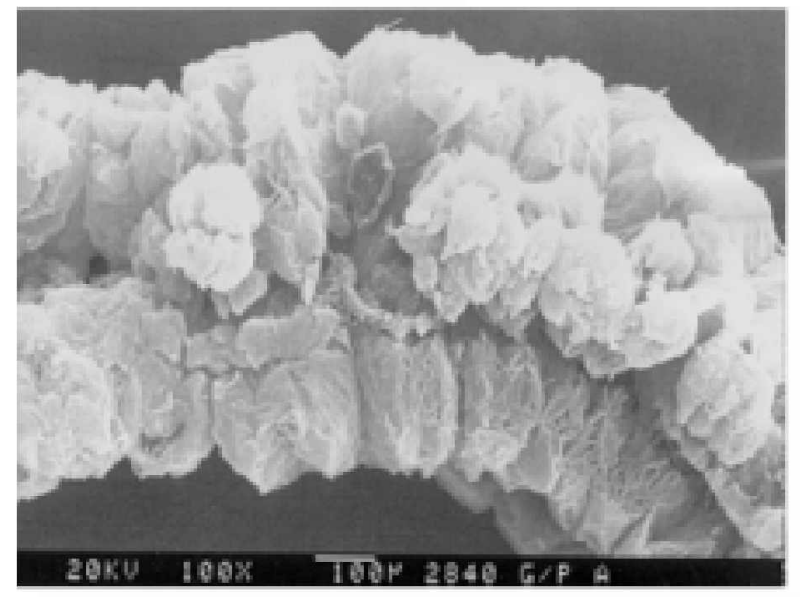

(c) 4100 thickness of $\mathrm{SO}_{3}$ molecular layers composed of double layer is calculated to be $6.52-7.44 \mathrm{~A}$. because van der Waals radius of sulfur and oxygen atom is $1.86 \mathrm{~A}$ and $1.40 \mathrm{~A}$. respectively: This value is similar to the gallery height $(8.3 \mathrm{~A})$ of GIC

Figure 5 exhibits the bulk density and expansion ratio of the exfoliated graphite with reaction time. The bulk density and the expansion ratio becomes constant as $\sim 0.0053 \mathrm{~g} / \mathrm{cm}^{3}$ and $\sim 400$. respectively: after $15 \mathrm{hr}$ reation, corresponding to the maximum intercalation of $\mathrm{SO}_{3}$ into graphite interlayer. This result compared with that in a residue compound of sulfuric acid. proving a practical reaction of $\mathrm{SO}_{3}$ molecules with $\pi$-electron in graphite interlayer. The introduction of $\mathrm{SO}_{3}$ molecules into the graphite layer can not be achieved by the direct immersion of graphite in concentrated sulfuric acid itself. $\mathrm{SO}_{3}$ molecules in sulfuric acid can not interact with the $\pi$-electron in graphite interlayer. because it already taken a needed electron from the water molecules.

Figure 6 exhibits the pore characteristic of the exfoliated graphite determined by mercury porosimetry. Here, the exfoliated graphite was prepared by the reaction for $15 \mathrm{hr}$. Pore size was mainly in the range of $10-170 \mu \mathrm{m}$ with $3.3 \times$ $10^{-2} \mathrm{~m}^{3} / \mathrm{kg}$ of pore volume. This pore property, as shown in Figure 7. was well proved in surface morphology. Exfoliated structure to prove full expansion among each plates is

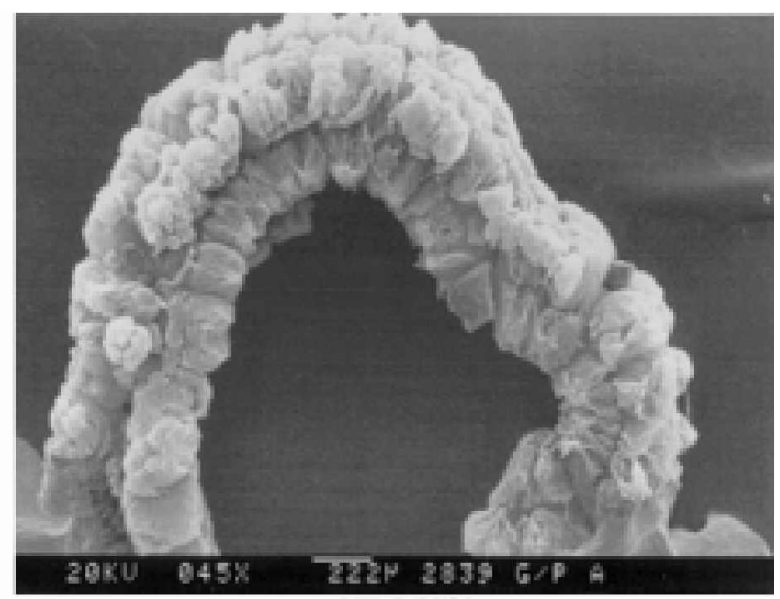

(b) $\times 45$

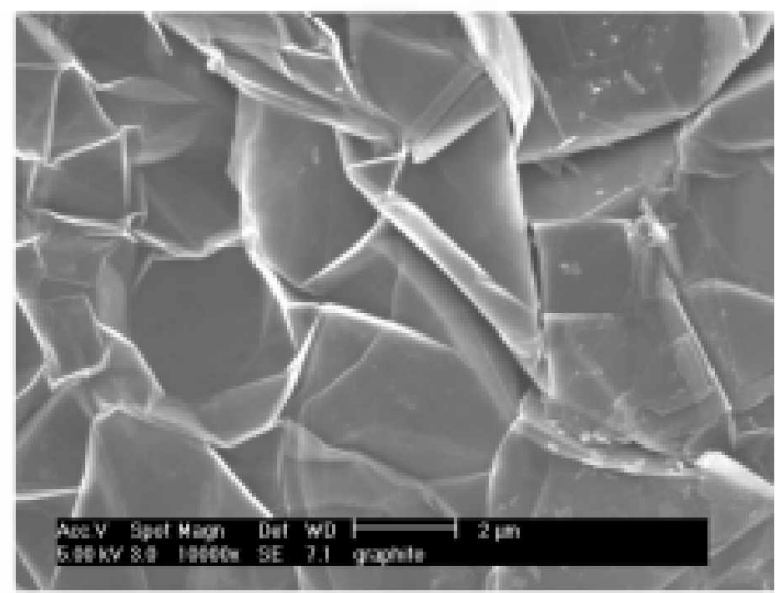

(d) $\times 10.000$

Figure 7. SEM (scanting electron micrographs) for exfoliated graphite. 


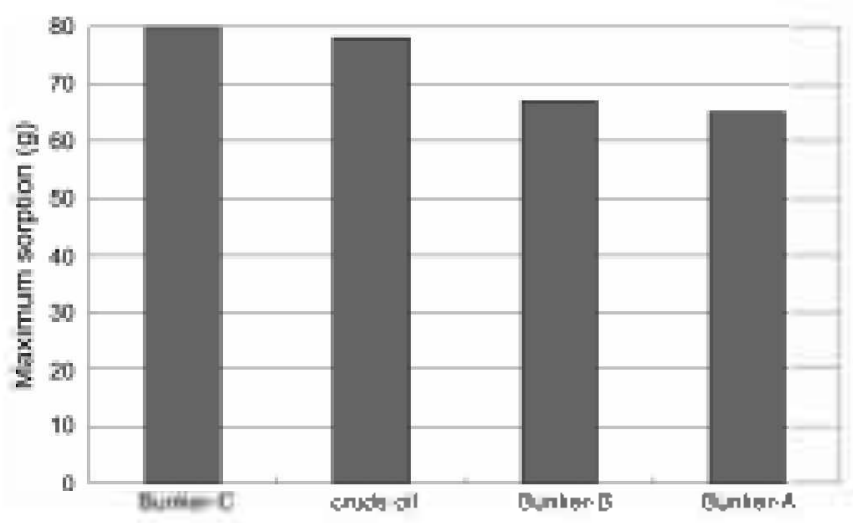

Figure 8. Maximumn sorption capacity of the exfoliated graphite for different grade heavy oil.

exhibited well in surface morphology. resulting in a numerous and complicated open canals. This macropore can be more useful for the absorption of oil with more viscous and large molecular weight. In particular. the absorption into exfoliated graphite with macroporous and highly hydrophobic property can be rapidly performed to large amount of oil resulted from capillary condensation. In figure 8 . the maximum sorption capacity in this exfoliated graphite with bulk density $0.0053 \mathrm{~g} / \mathrm{cm}^{3}$ was found to be $80 \mathrm{~g}$ of bunker-C. $78 \mathrm{~g}$ of crude oil. $67 \mathrm{~g}$ of bunker-B and $65 \mathrm{~g}$ of bunker-A per $\mathrm{l} \mathrm{g}$ of exfoliated graphite. respectively and the adsorption completed within several minutes. The adsorbed quantity is in direct proportion to the viscosity and molecular weight of oily class. It depends on the macro porous structure in exfoliated graphite. The adsorbed capacity of oily materials is far above exfoliated graphite's pore volume. Shen et al. explained this result by exfoliated graphite's unique "winding and adsorbing space".11 After adsorbing heavy oil. exfoliated graphite's particles form into "lumps" which are visible to the naked eye. It was caused by changing exfoliated graphite's internal stress during the adsorption. The dexfoliated graphite particles mesh with each other. took a shape of lump and formed additional adsorbing space. The sizes of the lump and "winding and adsorbing space" were ralated with exfoliated graphite's porous structure. surface tension between exfoliated graphite and aborbing agent and cohesion of absorbing agent itself.

In conclusion. this result indicates clearly that the direct reaction of $\mathrm{SO}_{3}$ gas with the graphite particle can be another route leading to the exfoliated graphite with excellent physical properties. This process can utilize $\mathrm{SO}_{3}$ gas which can be produced as the byproduct in a chemical process. proceed without discharge of acid waste. and solve a problem in the process caused by treating a conrosive and strong acid admixtures in wet process. In particular. intercalated $\mathrm{SO}_{3}$ molecules may have a role as seducer to take a numerous organic and inorganic molecules into graphite interlayer because of their strong reactivity: This success of $\mathrm{SO}_{3}$ gas implies that another oxidative gases can be used for the preparation of exfoliated graphite.

\section{Conclusion}

The direct reaction of $\mathrm{SO}_{3}$ gas with the graphite particle resulted in GIC with $8.3 \AA$ in gallery height. which indicates that $\mathrm{SO}_{3}$ molecules can configure with double or multiple layers in the interlayer. The maximum intercalation of $\mathrm{SO}_{3}$ into graphite interlayer was completed after $15 \mathrm{hr}$ reaction. The severe heating of GIC obtained from the reaction for 15 $\mathrm{hr}$ resulted in producing exfoliated graphite. The bulk density and expansion ratio of exfoliated graphite were $\sim 0.0053 \mathrm{~g} / \mathrm{cm}^{3}$ and $\sim 400$, respectively. Pore size was mainly in the range of $10-170 \mu \mathrm{m}$. and $3.3 \times 10^{-2} \mathrm{~m} / \mathrm{kg}$ of pore volume. Surface morphology well exhibited exfoliated structure to prove full expansion among each plate. showing a numerous and complicated open canals. The maximum sorption capacities in exfoliated graphite with bulk density $0.0053 \mathrm{~g} / \mathrm{cm}^{3}$ were found to be $80 \mathrm{~g}$ of bunker-C. $78 \mathrm{~g}$ of crude oil. $67 \mathrm{~g}$ of bunker-B and $65 \mathrm{~g}$ of bunker-A per $\mathrm{l} \mathrm{g}$ of exfoliated graphite. respectively. and the adsorption completed within several minutes. This result indicates that the direct reaction of graphite particles with gaseous $\mathrm{SO}_{3}$ can be proposed as an another route for the exfoliated graphite having excellent plysical properties

\section{References}

1. Kang. F. Y; Inagaki, M; Shen, W. C.: Cao. N. Z.: Gu. J. L. Adsorption Behavior of Heav Oil on Exfoliated Graphite: International Symposium of Carbon. 1998: p 295.

2. Toyoda. M.: Moriya. K.: Aizawa. T.: Inagaki. M. Sontion and Reconery of Heany Oil by Ling Exfoliated Grophite: International Symposium of Carbon, 1998: 1356.

3. Toyoda M Inagaki. M. Carbon 2000. 38, 199.

4. Avideev. V. V.: Martynov. I. Y.: Nikol'skaya. I. V: Monyakina. L. A.: Sorokina. N. E. J. Phys. Chem. Solids 1996. 57.837.

5. Avdeev. V. V.: Sorokina. N. E.: Martynof. I. Y:: Monyakina. L. A.: Nikol'skaya, I. V. Inorganic Materials 1997, 33. 579.

6. Berger. D.: Maire. J. Mater. Sci. Eng. 1977. $31,335$.

7. Yoshida, A.: Hishivama, Y.: Inagaki. M. Corbon 1991, 29. 1227.

8. Kang. F. Y.: Leng. Y.: Zhang. T. Y. Carbon 1997. 35. 1089.

9. Inagaki. M.: Wang. Z. D. Carbon 1992. 30.869.

10. Skaf. D. W.: Edwards. J. K. Sm. Met. 1992, 46,137

11. Bourelle. E:; Douglade. J:- Metrot, A. Mol. Crnst Liq. Cnst. 1994. 2H, 227.

12. Inagaki, M.; Muramatsu. K.: Maekawa, K.: Tanabe, Y. Tanso 1985. 123.160.

13. Inagaki. M.: Shiwachi. Y.: Maeda. Y. J. Chem. Plys. 1984. 84. 847 .

14. Tanaike. O; Inagaki, M. Corbon 1997.37, 1760

15. Shen, W. C; Cao. N. Z.: Zhou. L.; Kang, F. Y; Gu. J. L. LiquidPhase Adsorption Perfonmance on Expanded Graphite: International Symposium of Carbon. 1998: p 384 